\title{
FAS-670 Gene Promoter Region Polymorphism in Cervical Intraepithelial Neoplasia Grade 3 (CIN 3) and Invasive Cervical Cancer
}

\author{
Edison Fedrizzi*, Flavio Zucchi, Sylvia Brenna, Cristina Valletta de Carvalho, \\ Fabricio Silva, Ana Massad Costa, Ismael Guerreiro da Silva
}

Federal University of Santa Catarina, Florianópolis, Brazil

Email: ${ }^{*}$ enfedrizzi@uol.com.br

Received 24 March 2015; accepted 23 May 2015; published 27 May 2015

Copyright (C 2015 by authors and Scientific Research Publishing Inc.

This work is licensed under the Creative Commons Attribution International License (CC BY).

http://creativecommons.org/licenses/by/4.0/

(c) (i) Open Access

\section{Abstract}

The human papillomavirus (HPV) is the etiologic agent of genital cancer, but alone it is incapable of inducing oncogenesis. Rather, progression to invasive lesions is associated with host immunity and interference in the process of cellular apoptosis. Among the several genes involved in cell death, the FAS gene appears to be an important factor. The aim of this study was to evaluate whether there is an association between polymorphisms of the $F A S-670$ gene promoter region and preinvasive and invasive lesions of the cervix. The FAS gene was evaluated for the presence of polymorphisms using polymerase chain reaction and restriction fragment length polymorphism techniques in 225 blood samples for the control group, as well as cervical tissue from patients with cervical intraepithelial neoplasia grade 3 (CIN 3; 75 cases) or invasive carcinoma (214 cases). The AG genotype of the $F A S$ - 670 gene promoter region was significantly more frequent in women with CIN 3, with an estimated risk of three times $(\mathrm{OR}=3.0)$. No difference, however, was observed in the control group and women with cervical cancer. In women with cancer, the genotypes were similar in the different histological types and degree of tumor differentiation. Assessing allelic distribution (A or G), we observed no difference in frequency of genotypes in studied groups. These data suggest that polymorphism of the promoter region of the FAS-670 gene is associated with increased risk of CIN 3, but not for invasive cancer of the cervix.

\section{Keywords}

FAS, Genetic Polymorphism, CIN 3, Uterine Cervical Neoplasms, Apoptosis

${ }^{*}$ Corresponding author.

How to cite this paper: Fedrizzi, E., Zucchi, F., Brenna, S., de Carvalho, C.V., Silva, F., Costa, A.M. and da Silva, I.G. (2015) FAS-670 Gene Promoter Region Polymorphism in Cervical Intraepithelial Neoplasia Grade 3 (CIN 3) and Invasive Cervical Cancer. Journal of Cancer Therapy, 6, 434-445. http://dx.doi.org/10.4236/jct.2015.65047 


\section{Introduction}

Cervical cancer affects thousands of women around the world (471,000 cases per year) and is the second leading cause of death from cancer in women. Approximately $80 \%$ of cases occur in developing countries, where, in some regions, it is the most common form of cancer in women [1]. Brazil has one of the highest incidence rates of this neoplasia, reaching upwards of 50 - 83 cases per 100,000 women in some regions [1]. For the year 2014, the estimated incidence of cervical cancer was 18,503 new cases, and the estimated risk was 15.3 cases per 100,000 women, with the highest incidence being in the north of the country $(23 / 100,000)$ [2].

The etiology of cervical cancer has been studied for over 150 years, and it is often associated with infection. With the recent advent of molecular biology, cervical cancer tumors were determined to arise partially from a sexually transmitted infectious agent, the human papillomavirus (HPV) [3]-[5]. This virus is present in more than $99.7 \%$ of cases of squamous-cell carcinoma of the cervix, and the remaining $0.3 \%$ may be associated with unknown type of HPV [6] [7].

Despite the high frequency of infection, the prevalence of intraepithelial lesions and cervical cancer is low. The natural history of HPV infection shows that most infections are transient (80\%) and not associated with the detected cytological abnormalities [8]. Therefore, HPV alone is incapable of inducing cancer, although the reasons are poorly understood. One possible explanation is that other factors (cofactors) in addition to HPV are needed for the development of this neoplasm [9] [10]. For example, in addition to sexual activity, multiparity, chronic genital infections, hormonal and immunological alterations, other sexually transmitted diseases, contraceptives and smoking are important factors [8]. Possibly the most important factors are those that affect host immunity. Most of these cofactors alter the ability of the host to respond immunologically; thus, the host is more likely to be a chronic carrier of HPV, to show cellular transformation, or both [11].

The role of host genetic factors in cervical carcinogenesis is still poorly understood. Investigations are now focusing on new molecular markers associated with susceptibility to the development of cervical carcinoma, known as biomarkers of progression, such as loss of heterozygosity, FHIT, telomerase, DNA ploidy, PCNA, Ki67, p16, Mcm and Cdc6. Recently, a polymorphism in the promoter region of the FAS gene was shown to be associated with cervical oncogenesis in some studies, [12]-[15] but not in others [16]-[20].

The gene for the FAS receptor (also known as APO-1, CD95 or TNFRSF6) with its ligand (FASL) plays an essential role in the physiological regulation of apoptosis [21] [22] and transmission of no apoptotic signals [23]. At least twenty FAS receptor gene mutations have been described in humans and may trigger pathogenesis of many human diseases [24].

In addition to mutations, genetic elements located in the promoter region, such as polymorphisms, which influence the transcriptional activity of this gene [16], affect expression of these genes. Huang et al identified two polymorphisms in the FAS promoter region, which were A/G substitutions at position 670 and 1377 of the amplifier region [25]. The presence of the FAS-670 promoter region A/G polymorphism has been described in several diseases, such as rheumatoid arthritis, systemic lupus erythematosus, [26] multiple sclerosis, [27] lung carcinoma, [28] [29] and carcinoma of the nasopharynx, [30] among others. However, few studies have shown an association between FAS gene polymorphisms and cervical carcinogenesis [12] [14]-[16] [20].

The aims of this study were to evaluate the FAS gene promoter region polymorphism at position-670 in blood samples (control group) and in cervical tissue with precancerous lesions (cervical intraepithelial neoplasia grade 3-CIN 3) and invasive cervical carcinoma to determine whether this polymorphism was associated with the pathogenesis of cervical carcinoma.

\section{Materials and Methods}

\subsection{Patients}

This study was observational and case-controlled. The sample size was calculated with Epi-Info 6.04 software based on reports of FAS gene polymorphisms being present in 90\% of CIN 3 cases, $82 \%$ of cervical cancer cases and $70 \%$ in women without these diseases [13] [31].

We evaluated 514 cases, including 225 cases of women with normal cytology and colposcopy (control), 75 histologically proven cases of CIN 3 and 214 cases of invasive cervical carcinoma. These cases were observed on the Gynecology and Obstetrics Service of the University Hospital at the Federal University of Santa Catarina (UFSC) in Florianopolis, the Alfredo Abraão Cancer Hospital in Campo Grande, São Paulo Hospital of Escola Paulista de Medicina in São Paulo and the Hospital and Maternity Leonor Mendes de Barros in São Paulo, Brazil. 
The exclusion criteria for the control group included women who were previously subjected to anticancer treatment (radiotherapy or chemotherapy) for any type of cancer. For the CIN 3 group, we excluded cases associated with invasive or micro invasive lesions, and for the invasive cancer group, we excluded cases of cervical carcinoma in which the primary lesion site was doubtful, cases with possible endometrial or adjacent-organ carcinoma (bladder or rectum) with involvement of the cervix and cervical carcinoma cases that was previously treated with radiotherapy and/or chemotherapy.

Women were divided by age into $\leq 50$ years old and $>50$ years old for the purpose of dividing women by menopausal status; the average age of menopause among Brazilian women is approximately 50 years old [32]. Other factors evaluated were ethnicity (white, black and Asian), the histological type of carcinoma (squamous carcinoma or adenocarcinoma) and the tumor grade (G1 for well differentiated cervical tumors, G2 for moderately differentiated tumors and G3 for poorly differentiated or undifferentiated tumors). For calculation of risk estimates, we grouped grades G1 and G2, which were considered less aggressive, and compared them with G3, which was regarded as more aggressive [33].

\subsection{Procedures}

The presence of the FAS gene polymorphism was determined using polymerase chain reaction (PCR) and restriction fragment length polymorphism (RFLP) after DNA extraction of paraffined tissue and blood.

\subsubsection{DNA Extraction: Paraffin Block (Technical Formaldehyde/Chloroform)}

The most representative paraffin blocks from the CIN 3 group and the cervical carcinoma group were selected for the study. Small fragments of each block were washed three times with $1 \mathrm{~mL}$ xylene for 10 minutes each in a 2-mL Eppendorf vial. The material was then agitated at 200 revolutions per minute (rpm) at $37^{\circ} \mathrm{C}$ for 30 minutes. Samples were then washed twice with $1 \mathrm{~mL}$ of absolute ethanol, then washed with $1 \mathrm{~mL}$ of $50 \%$ ethanol and finally washed with $1 \mathrm{~mL}$ of autoclaved MilliQ water. Between each wash, the vials were shaken at $200 \mathrm{rpm}$ for 30 minutes at $37^{\circ} \mathrm{C}$ and centrifuged at 13,000 rpm for 1 minute, and the supernatant was discarded. Then, 200 $\mu \mathrm{L}$ of digestion buffer was combined with $10 \mu \mathrm{L}$ of proteinase $\mathrm{K}$ and heated to $37^{\circ} \mathrm{C}$ overnight or for 48 hours. This material was then centrifuged at 13,000 rpm for 1 minute. An equal volume of the DNA product GFX ${ }^{\circledR}$ was added to the supernatant and centrifuged at $13,000 \mathrm{rpm}$ for 10 minutes. Then, $200 \mu \mathrm{L}$ of supernatant was placed in a new $1.5 \mathrm{~mL}$ Eppendorf vial, and $950 \mu \mathrm{L}$ of absolute ethanol and $20 \mu \mathrm{L}$ of $3 \mathrm{M}$ sodium acetate (pH 5.2) were added. This solution was kept at $-20^{\circ} \mathrm{C}$ for 24 hours and subsequently centrifuged at $13,000 \mathrm{rpm}$ for 20 minutes to form a DNA pellet, which was washed with $80 \%$ ethanol and centrifuged at 13,000 rpm for 2 minutes twice. The residue of this process was dried at room temperature for 10 minutes and rehydrated in $100 \mu \mathrm{L}$ of autoclaved MilliQ water. At that point, the DNA was ready to be used in other reactions.

\subsubsection{DNA Extraction: Blood (According to the GFX Kit@)}

For blood samples, genomic DNA was extracted using the GFX ${ }^{\circledR}$ kit for blood cells (Amersham-Pharmacia). A total of $100 \mu \mathrm{L}$ of whole blood was supplemented with $500 \mu \mathrm{L}$ of extraction solution, and the mixture was kept at rest for 5 minutes. Then, the mixture was added to a column filter and centrifuged at $8000 \mathrm{rpm}$ for 1 minute. Then, $500 \mu \mathrm{L}$ of the wash solution was added, the product was centrifuged at 14,000 rpm for 3 minutes, and 100 $\mu \mathrm{L}$ of autoclaved MilliQ water was added, preheated to $70^{\circ} \mathrm{C}$ and centrifuged at $14,000 \mathrm{rpm}$ for 1 minute in a new Eppendorf vial. DNA was then ready to be used in other reactions.

\subsubsection{DNA Amplification by PCR}

To investigate the FAS gene polymorphism of the promoter region (amino acid position-670), we used the technique described by Rudert et al. [34] and Wang et al. [29], with the following primers to amplify the DNA fragment: forward: 5'-CTA CCT AAG AGC TAT CTA CCG TTC-3', reverse: 5'-GGC TGT CCA TGT TGT GGC TGC-3'.

\subsubsection{Identification of FAS Gene Polymorphism by Restriction Enzyme Digestion Using RFLP}

The restriction enzyme Mva1 cuts DNA at specific sites. When the mutation creates a new restriction site, the fragments generated are smaller than the fragments of non-mutated DNA. These fragments are then separated by 
the molecular weight through gel electrophoresis [35].

The wild-type FAS gene (A/A) showed two bands by agarose gel electrophoresis: a 233-base pair fragment and a 98-base pair fragment. This classification is considered less associated with diseases. In cases of heterozygosity (genotype A/G), the amplification and digestion of the FAS gene produced four bands of 233, 189, 98 and 44 base pairs. This classification is considered the most associated with disease. In cases of G/G mutation (FAS mutant), amplification and digestion with Mva1 produced bands of 189, 98 and 44 base pairs. In all three conditions, the total number of base pairs involved is 331.

Identification of the polymorphism begins with fragmentation of a $10 \mu \mathrm{L}$ aliquot of PCR product by Mva1 for approximately 4 hours or overnight at $37^{\circ} \mathrm{C}$. Next, the solution is subjected to gel electrophoresis using $2 \%$ agarose gels with ethidium bromide staining, sorting the Fas gene according to the base pairs identified.

\subsection{Statistical Analyses}

Data were analyzed using Statistical Package for Social Sciences (SPSS; version 16.0, IBM ${ }^{\circledR}$ ). To compare qualitative variables or frequencies in the form of proportions, we used Fisher's exact test. To compare quantitative age data, we initially used the Shapiro-Wilk test to verify that the data showed a normal distribution. With a p value of $<0.05$ ( $\operatorname{sig}=0.003$ ), the age variable did not show a normal distribution, so we used the Kruskal-Wallis and Mann-Whitney tests. The expected genotype frequencies (AA, AG, and GG) were estimated from the observed allele frequencies, and deviations from Hardy-Weinberg equilibrium were calculated using a chi-square test. For all tests, we considered levels of $5 \%$ statistically significant $(\mathrm{p}<0.05)$. For estimation of ratio values (odds ratio [OR]) between the case and control genotypes, the unconditional logistic regression test was performed with a 95\% confidence interval [36].

\subsection{Ethical Standards}

The research project was approved by the Federal University of Santa Catarina (opinion 057/07) and Escola Paulista de Medicina (opinion 0256/07) Ethics in Human Research Committee.

\section{Results}

\subsection{Demographic Feature of Study Population}

Age and FAS gene polymorphism variables were assessed in all 514 cases. However, the ethnicity variable could only be evaluated in approximately half of the cases (247 cases, divided into 3 groups: white, black and Asian). Of the 214 cases of carcinoma of the cervix, we only had access to the histological type and degree of tumor differentiation in approximately half of the cases (123). Analysis of these data is presented in Table 1.

The age distribution was very similar between the control group and the carcinoma group, with approximately half of the cases being women less than 50 years old. However, significantly more women from the CIN 3 group were younger than 50 years of age $(>90 \%)$, (Table 1$)$. Furthermore, the mean age was significantly different between the three groups $(\mathrm{p}<0.05)$. Specifically, the CIN 3 case group (mean age 36.91 years old) was significantly younger than the control group (mean age 46.87 years old), which was significantly younger than the cancer group (mean age 51.64 years old).

In evaluating the ethnicity variable, we observed a statistically significant difference among the three groups $(\mathrm{p}<0.05)$. Specifically, while there was no significant between the control group and the CIN 3 group ethnicity ( $\mathrm{p}=0.36$ ), the predominance of Caucasians among the cancer group (80\%) was significantly different from controls.

Of the 123 cases with a known histological type of cancer, the vast majority (112 cases) had the squamous carcinoma type (91.1\%), and the remainder (11 cases) had the adenocarcinoma type (8.9\%).

\subsection{Polymorphism Analysis}

In analyzing the observed and expected genotype distribution of FAS polymorphisms in all three groups, we found that the CIN 3 group did not meet Hardy-Weinberg equilibrium $(p<0.05)$ but the control and cancer groups did $(\mathrm{p}>0.05)$. 
Table 1. Distribution of demographic and clinical variables assessed in the study.

\begin{tabular}{|c|c|c|c|c|c|c|c|}
\hline \multirow{2}{*}{ Variable Category } & \multicolumn{2}{|c|}{ Control } & \multicolumn{2}{|c|}{ CIN 3} & \multicolumn{2}{|c|}{ Carcinoma } & \multirow{2}{*}{$\mathrm{P}^{*}$} \\
\hline & $\mathrm{n}$ & (\%) & $\mathrm{n}$ & $(\%)$ & $\mathrm{n}$ & (\%) & \\
\hline Age $(\mathrm{N}=514)$ & & & & & & & $<0.001$ \\
\hline - $<50 \mathrm{Y}$ & 130 & $(57.8)$ & 69 & $(92.0)$ & 110 & $(51.4)$ & \\
\hline - $>50 \mathrm{Y}$ & 95 & $(42.2)$ & 06 & $(08.0)$ & 104 & $(48.6)$ & \\
\hline Total & 225 & (100) & 75 & $(100)$ & 214 & $(100)$ & \\
\hline Ethnicity $(\mathrm{N}=247)$ & & & & & & & $<0.001$ \\
\hline - White & 20 & $(40.8)$ & 38 & $(50.7)$ & 98 & $(79.7)$ & \\
\hline - Black & 29 & $(59.2)$ & 37 & $(49.3)$ & 21 & $(17.1)$ & \\
\hline - Asian & 0 & (0) & 0 & (0) & 04 & $(03.3)$ & \\
\hline Total & 49 & $(100)$ & 75 & $(100)$ & 123 & $(100)$ & \\
\hline \multicolumn{8}{|l|}{ Histological Type $(\mathrm{N}=214)$} \\
\hline - Squamous carcinoma & & & & & 112 & $(91.1)$ & \\
\hline - Adenocarcinoma & & & & & 11 & $(08.9)$ & \\
\hline - Unknown & & & & & 91 & & \\
\hline Total & & & & & 214 & $(100)$ & \\
\hline Gene FAS Polymorphism $(\mathrm{N}=514)$ & & & & & & & 0.046 \\
\hline - Wild (AA) & 53 & $(23.5)$ & 08 & $(10.7)$ & 52 & $(24.3)$ & \\
\hline - Heterozygote (AG) & 112 & $(49.8)$ & 50 & $(66.7)$ & 104 & $(48.6)$ & \\
\hline - Mutant (GG) & 60 & $(26.7)$ & 17 & $(22.6)$ & 58 & $(27.1)$ & \\
\hline Total & 225 & (100) & 75 & (100) & 214 & (100) & \\
\hline
\end{tabular}

*Fisher exact test.

We evaluated the distribution of genotypes of the promoter region of the FAS-670 gene in the three groups, and we observed a statistically significant difference between them $(\mathrm{p}<0.05)$. Specifically, the CIN 3 group had a statistically significant higher prevalence of the AG genotype (66.7\%) (Figure 1). However, we found no significant difference between the control group and the cancer group in genetic composition of the promoter region ( $\mathrm{p}>0.05)$ (Table 2).

When we stratified age, we found that there was no association between genotype and increased risk for disease in either age group ( $\leq 50$ and $>50$ years old). In all three groups, the heterozygous genotype (AG) was the most frequent.

When comparing the genotypes of the FAS gene with known histological types of cervical carcinoma cases, we found no statistical difference between them, and the heterozygous genotype (AG) remained the most frequent, approximately $40 \%$ for both squamous carcinoma and adenocarcinoma.

\subsection{Allele Analysis}

We assessed the allelic distribution (A and G) of the promoter region of the FAS-670 gene in the three groups and found no significant difference ( $p>0.05$ ) (Table 3).

\subsection{Estimates of Independent Risk Factors (OR)}

Because the OR is an estimate of risk for developing the disease under study, we conducted a logistic regression analysis using the AA genotype as a reference. We included risk factors that were significant from individual case reviews. 


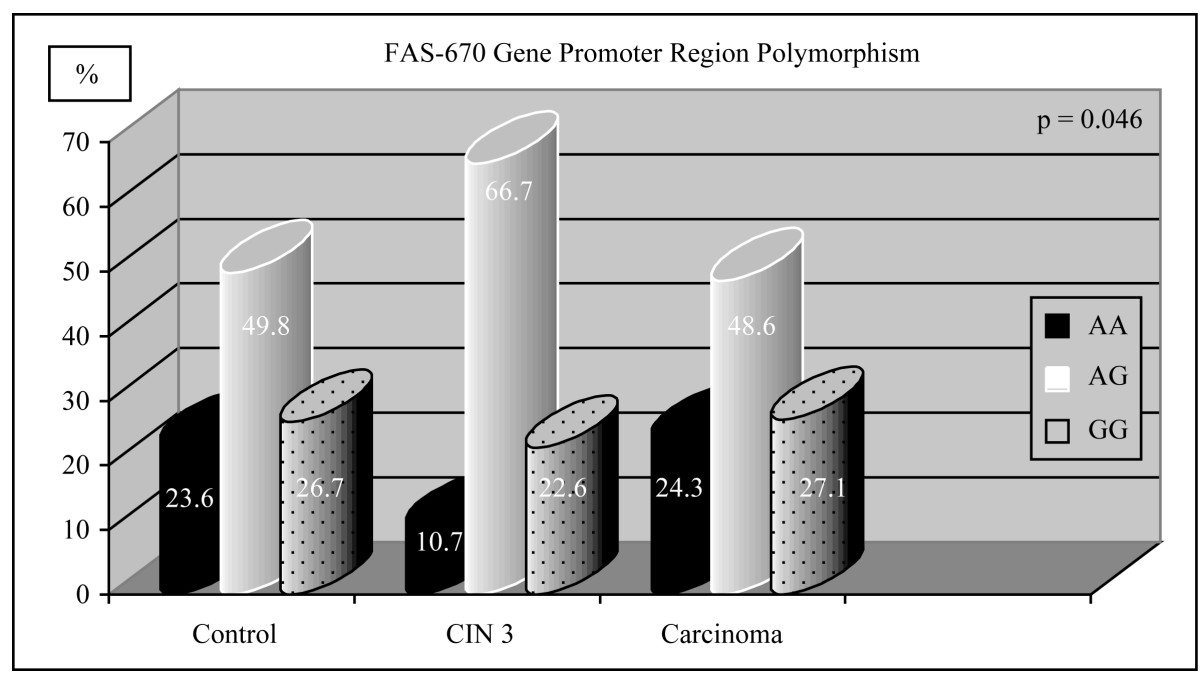

Figure 1. Polymorphism frequency of the FAS-670 promoter region in the studied groups.

Table 2. Genotypic frequency of the FAS-670 polymorphism in the studied groups.

\begin{tabular}{|c|c|c|c|c|c|c|c|c|c|}
\hline \multirow{3}{*}{ Status } & \multicolumn{8}{|c|}{ Polymorphism } & \multirow{3}{*}{$\begin{array}{l}\text { Fisher } \\
\text { exact test }\end{array}$} \\
\hline & \multicolumn{2}{|c|}{ AA } & \multicolumn{2}{|c|}{ AG } & \multicolumn{2}{|c|}{ GG } & \multicolumn{2}{|c|}{ Total } & \\
\hline & $\mathrm{n}$ & (\%) & $\mathrm{n}$ & (\%) & $\mathrm{n}$ & (\%) & $\mathrm{n}$ & $(\%)$ & \\
\hline Control & 53 & $(23.6)$ & 112 & $(49.8)$ & 60 & $(26.7)$ & 225 & 100.0 & 0.046 \\
\hline CIN 3 & 08 & $(10.7)$ & 50 & $(66.7)$ & 17 & $(22.6)$ & 75 & 100.0 & \\
\hline Cancer & 52 & $(24.3)$ & 104 & $(48.6)$ & 58 & $(27.1)$ & 214 & 100.0 & \\
\hline Total & 113 & $(22.0)$ & 266 & (51.8) & 135 & (26.3) & 514 & 100.0 & \\
\hline
\end{tabular}

Table 3. Distribution of allelic polymorphism of the FAS-670 gene in the studied groups.

\begin{tabular}{|c|c|c|c|c|c|c|c|}
\hline \multirow{3}{*}{ Status } & \multicolumn{6}{|c|}{ Allele } & \multirow{3}{*}{$\begin{array}{l}\text { Fisher } \\
\text { exact test }\end{array}$} \\
\hline & \multicolumn{2}{|c|}{ A } & \multicolumn{2}{|c|}{ G } & \multicolumn{2}{|c|}{ Total } & \\
\hline & $\mathrm{n}$ & (\%) & $\mathrm{n}$ & (\%) & $\mathrm{n}$ & (\%) & \\
\hline Control & 218 & (48.4) & 232 & (51.6) & 450 & 100.0 & 0.60 \\
\hline CIN 3 & 66 & $(44.0)$ & 84 & (56.0) & 150 & 100.0 & \\
\hline Cancer & 208 & $(48.6)$ & 220 & (51.4) & 428 & 100.0 & \\
\hline Total & 492 & (47.9) & 536 & (52.1) & 1028 & 100.0 & \\
\hline
\end{tabular}

Comparison of quantitative variables between the control group and the CIN 3 group revealed that only age was significantly different between groups upon individual analysis. The unadjusted risk estimate of genotype AG for the CIN 3 group was almost three times higher than the risk estimate for controls $(\mathrm{OR}=2.96$; $95 \% \mathrm{CI}=$ 1.31 - 6.68; $\mathrm{p}=0.01)$. Furthermore, this risk effect of the AG genotype remained even after adjusting for age $(\mathrm{OR}=3.04 ; 95 \% \mathrm{CI}=1.29-7.16 ; \mathrm{p}=0.01)$, suggesting that this variable was not a confounding, moderating or mediating factor in the relationship between the polymorphism and the disease under study.

Individual case analysis of the control group and the cancer group revealed that age and ethnicity were different between the groups. Analysis of unadjusted risk revealed that no genotype influenced cervical cancer ( $p>$ 0.05). Furthermore, inclusion of age and ethnicity variables did not change the results, suggesting that these variables were not confounding, moderating or mediating factors of the relationship between polymorphism and 
cervical cancer, i.e., the genotype had no influence on cancer $(\mathrm{p}>0.05)$ (Table 4).

We also analyzed cases of carcinoma, grouping women by age into $\leq 50$ years and $>50$ years. Using the AA genotype as the reference value, we found that no genotype of the promoter region of the FAS-670 gene had any greater influence on cancer risk, independent of age.

Finally, we assessed cases of carcinoma using squamous carcinoma as a benchmark, and we found that no genotype of the FAS-670 gene influenced the histological type. Furthermore, using the tumor grades G1 and G2 as benchmarks, we found that no genotype was associated with increased tumor aggressiveness.

\section{Discussion}

Cervical cancer is still one of the most common causes of cancer and death among women in developing countries. Although the role of high-risk HPV in cervical carcinogenesis is evident, only a small proportion of these cases progress to an invasive form of the disease [37], indicating that the development of cervical carcinoma is influenced by other factors, likely including genetic factors [19]. Decreased expression of the FAS gene and/or increased expression of its ligand (FASL) have been demonstrated in many types of human cancer and appear to be associated with human carcinogenesis and more aggressive tumors [38] [39]. Several factors must be considered before addressing the role of FAS gene polymorphisms in cervical cancer susceptibility. First, we should consider the geographical location and ethnic group under study. Although the AA genotype is considered normal [25], we can see in Table 4 that distribution of the FAS-670 gene polymorphism is similar among the normal population in different countries, with the AG genotype (heterozygote) being the most commonly found (in approximately half the cases), followed by AA (wild-type) and finally GG (mutated) [12] [16] [19] [25] [27] [30] [40]-[43], just as we found in our study. In contrast, cases in Asian countries showed a much lower frequency of the GG genotype than other countries.

Individual phenotypic variations are often the result of slight differences in the sequence in the coding region

Table 4. A/G polymorphism distribution of the FAS gene at position-670 in the population of different geographical regions.

\begin{tabular}{ccccc}
\hline & & & Genotype (\%) & \\
Author/Year & Country & AA & AG & GG \\
\cline { 3 - 5 } Nelson, 2001 & USA & 30.8 & 46.0 & 23.2 \\
Huang, 1997 & Australia & 23.5 & 51.7 & 24.7 \\
Niino, 2002 & Japan & 27.3 & 52.1 & 20.7 \\
Seo, 2002 & Korea & 34.9 & 48.6 & 16.5 \\
Lai, 2003 & Taiwan & 26.0 & 53.7 & 20.3 \\
Dybikowska, 2004 & Poland & 29.2 & 52.3 & 18.4 \\
Lai, 2005 & Taiwan & 28.6 & 50.6 & 20.8 \\
Sun, 2005 & China & 43.6 & 44.2 & 12.2 \\
Ueda, 2005 & Japan & 30.2 & - & - \\
Ueda, 2006 & Japan & 24.2 & 56.8 & 18.9 \\
Jrad, 2006 & Tunisia & 31.2 & 50.8 & 17.8 \\
Park, 2006 & Korea & 27.8 & 52.8 & 19.4 \\
Kang, 2008 & Korea & 35.4 & 51.9 & 12.7 \\
Mean & & $\mathbf{3 0 . 2}$ & $\mathbf{5 0 . 9}$ & $\mathbf{1 8 . 8}$ \\
Present study & Brazil & 23.5 & 49.8 & 26.7 \\
\hline GG: & & & & \\
\hline
\end{tabular}

*AG + GG: 69.8\%; Dybikowska et al. Int J Mol Med 2004; 14(3): 475-8; Lai et al. Gynecol Oncol 2005; 99: 113-8; Ueda et al. Int J Gynecol Cancer 2006; 16: 179-82; Kang et al. Cancer Gene Cytogen 2008; 180: 1-5. 
of the gene responsible for this phenotypic trait [25]. For example, variation in the promoter region of the FAS gene (position-670) may lead to different levels of expression of this gene. In addition, changes in the expression of the FAS gene can result in loss of or decrease in apoptotic function and, consequently, development of a disease or tumor [16]. This polymorphism has been studied in many diseases of infectious, immune or tumoral origin [26] [31] [38] [44]-[49]. More recently, studies have shown association between the polymorphism and preinvasive and invasive diseases of the cervix [12] [14]-[17] [20] [31] [42] [50]. In this study, we analyzed the FAS-670 gene promoter region polymorphism as a potential genetic marker for cervical carcinogenesis. Analysis of genotypes of this gene in cases of precancerous lesions, such as CIN 3, revealed a significant difference in the prevalence of genotype AG in cases with an adjusted risk estimate of three-fold. Similarly, Ueda et al. examined cervical smears and noted that the $G$ allele frequency increased from low-grade lesions to high-grade lesions (specifically, high-grade cervical squamous intraepithelial lesion [HSIL]) and that there was an increased OR for the G allele in HSIL compared with the control group [31]. The authors concluded that this increased frequency of AG or GG genotypes in HSIL could result in a significant reduction in the expression of the FAS gene and a subsequent decrease in apoptosis of cells with injury. Furthermore, Lai et al. reported a significant difference in the AA genotype in the HSIL and cancer group compared with the control group (AA: $38 \%$ vs. 28.6\%, respectively), with an estimated risk of 1.7 [42].

Because HPV infection with high oncogenic risk is inversely correlated with apoptosis of cervical epithelial cells, it is relevant to suggest that the presence of the FAS-670 G allele, which is associated with a lower expression of FAS efficiency, may be a risk factor for cervical carcinogenesis [19]. However, studies investigating the FAS gene and cervical cancer have been very controversial. For example, one study in a Taiwanese population showed that the FAS-670 A allele was associated with an increased risk of squamous intraepithelial lesions and squamous-cell carcinoma [12]. However, Ueda et al. showed that the GG genotype was associated with an increased risk of cervical cancer in the Japanese population [13]. Contrary to these two studies, five other studies [16]-[20] reported that the FAS-670 polymorphism was not associated with an increased risk of cervical carcinoma, similar to our findings. Comparison of the association between the FAS-670 polymorphism and cervical cancer is presented in Figure 2. The risk to develop cervical cancer resulted from this combined analysis was not increased $(\mathrm{OR}=1.28$; $95 \% \mathrm{CI}=0.69-1.87$; $\mathrm{p}>0.05)$. However, the tumor histologic type should be considered, despite the small number of no squamous cervical carcinoma in all studies. Zoodsma et al. observed that the FAS polymorphism was weakly associated with adenocarcinoma of the cervix but not epidermoid carcinoma [18]. Our results showed no association between any FAS genotype and the histological type or degree of tumor differentiation. Similarly, other authors found no significant association between an increased risk of cervical carcinoma, advanced stage or histological type and polymorphisms in the FAS gene [16] [19] [20]. Sun et al.

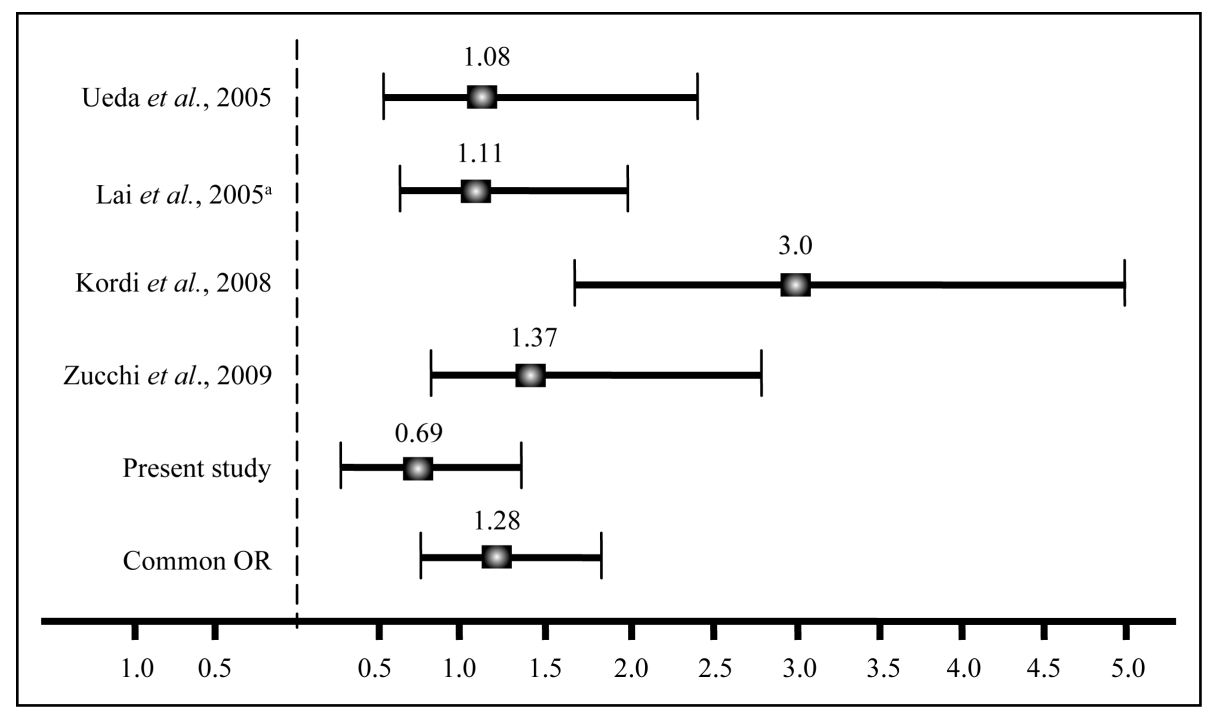

Figure 2. The association between FAS-670 gene polymorphism and cervical cancer. Date are reported odds ratio and 95\% confidence interval for the presence of the AG genotype. ${ }^{a}$ Lai et al., 2005: HSIL + squamous cell carcinoma. 
assessed risk of cervical cancer among Chinese women with FAS and FASL polymorphisms and found that only the FASL -844 gene polymorphism (i.e., switching of $\mathrm{C}$ to $\mathrm{T}$ ) was associated with an increased risk of cancer [51]. Differences in samples, techniques and genomic variation of the FAS-670 gene among different ethnicities may explain the discrepancy of these results.

HPV infection is a necessary condition for genital cancer. However, HPV needs to be coupled with other factors for oncogenesis to occur [52] [53]. Among these factors, the most important are smoking, multiparity, immunodeficiency, diet and other concomitant infections (mainly Chlamydia trachomatis and herpes simplex 2). Polymorphisms of the FAS and FASL genes may increase the risk of cancer by interacting with these environmental factors. For example, Zhang et al. reported a significant interaction between FAS gene polymorphisms and smoking and lung cancer [54]. In addition, Sun et al. observed that the polymorphisms of the FAS and FASL genes' promoter regions were associated with the development of esophageal squamous-cell carcinoma in a Chinese population of tobacco users [55]. The fact that smoking may increase expression of FASL [56] [57] and increase susceptibility to lung cancer and esophageal cancer suggests that this gene-environment interaction may have important implications for the development of human cancer related to tobacco [54]. However, Park et al. evaluated three different types of gene polymorphisms of FAS and FASL in a Korean population and found no association, either alone or in combination, with other risk factors of lung cancer [43]. Several studies in recent years have shown a correlation between smoking and cervical cancer [8] [10] [58] [59] while others have not [9] [60] [61]. The Multicenter Study Program of Cervical Cancer of the International Agency for Research on Cancer (IARC) reviewed the evidence concerning smoking and cervical cancer and concluded that smoking is an independent risk factor for this type of cancer [62]. Mechanisms associated with cervical carcinogenesis and smoking include inhibition of apoptosis by nicotine leading to tumor growth [10] [63] and increased expression of FAS and FASL genes on lymphocytes by metabolites of smoking, which increases lymphocyte apoptosis [57]. However, no studies have assessed the association between smoking, polymorphisms of the FAS gene and cervical cancer, except Kordi et al., which observed high risk of cervical cancer in passive smokers with AG genotype (OR = 4.6) [14].

Another cofactor that could interact with the FAS gene is hormones. As for tobacco, the IARC Multicenter Study Program of Cervical Cancer has demonstrated that the use of oral contraceptives for more than five years significantly increases the risk of cervical cancer $(\mathrm{OR}=2.72)$, especially after 10 years $(\mathrm{OR}=4.48)$ [62]. Estrogen can trigger apoptosis of $\mathrm{T}$ cells by increasing expression of FAS and FASL in cancer cells. Using a nonclassical mechanism, the estrogen receptor can regulate this expression by interacting with other substances [42] [64]. In our study, we attempted to assess the hormonal factor using menopausal status by separating women into age groups of greater or less than 50 years of age, which is the average menopause age among Brazilian women [32]. However, the age factor was not correlated with the frequency of FAS genotypes or the increased risk of cervical cancer.

Our study had some limitations. First, the sample size may have prevented us from finding an association between FAS polymorphisms and susceptibility to cervical cancer. Second, polymorphism of the FAS gene has a variable penetrance over time [65] and perhaps the age of the women may have interfered in these results, since we observed a significant association of genotype AG with CIN 3 (younger women) and not significant association with cancer (older women) compared to the control group. Third, the control group was not proportional to the cases in relation to the region, whereby the racial factor or mainly ancestry [66] could influence the results. Fourth, the HPV type was not assessed. It is possible that some specific type of HPV may suffer interference from any genotype of FAS gene and lead to the persistent infection and cervical oncogenesis. And finally, we did not include information on other exposure factors, which may alter the results and explain the conflict between our findings and those of several studies in the literature.

\section{Conclusion}

The authors conclude that the different genotypes of the FAS gene (position-670) promoter region are not associated with cervical carcinogenesis. However, our data suggest a possible relationship between increased risk of CIN 3 and the AG genotype, with risk being increased three-fold when adjusted for the age variable. Future studies should correlate the cofactors associated with carcinogenesis. These studies will show whether this polymorphism may be used as a genetic marker of susceptibility to the development of cervical cancer. 


\section{References}

[1] Franco, E.L. (1995) Epidemiology of Breast and Gynecological Cancer. In: Abrão, F.S., Ed., Treaty of Genital and Breast Cancer, Editora Roca, São Paulo, 145-167.

[2] Bruni, L., Barrionuevo-Rosas, L., Serrano, B., et al. (2014) ICO Information Centre on HPV and Cancer (HPV Information Centre). Human Papillomavirus and Related Diseases in Brazil, Summary Report 2014.

[3] Zur Hausen, H. (1986) Intracellular Survilance of Persisting Viral Infection: Human Genital Cancer Resulting from a Failing Cellular Control of Papillomavirus Gene Expression. Lancet, ii, 489-491. http://dx.doi.org/10.1016/S0140-6736(86)90360-0

[4] Herrington, C.S. (1994) Human Papillomaviruses and Cervical Neoplasia. I: Classification, Virology, Pathology and Epidemiology. Journal of Clinical Pathology, 47, 1066-1072. http://dx.doi.org/10.1136/jcp.47.12.1066

[5] Walboomers, J.M.M., Jacobs, M.V., Manos, M.M., et al. (1999) Human Papillomavirus Is a Necessary Cause of Invasive Cervical Cancer Worldwide. The Journal of Pathology, 189, 12-19. http://dx.doi.org/10.1002/(SICI)1096-9896(199909)189:1<12::AID-PATH431>3.0.CO;2-F

[6] Mougin, C., Dalstein, V., Pretet, J.L., et al. (2001) Epidemiology of Cervical Papillomavirus Infections. Recent Knowledge. La Presse Médicale, 30, 1017-1023.

[7] Adams, M., Borysiewicz, L., Fiander, A., et al. (2001) Clinical Studies of Human Papillomavirus Vaccines in Pre-Invasive and Invasive Cancer. Vaccine, 19, 2549-2556. http://dx.doi.org/10.1016/S0264-410X(00)00488-6

[8] Deacon, J.M., Evans, C.D., Yule, R., et al. (2000) Sexual Behaviour and Smoking as Determinants of Cervical HPV Infection and of CIN 3 among Those Infected: A Case-Control Study Nested within the Manchester Cohort. British Journal of Cancer, 88, 1565-1572. http://dx.doi.org/10.1054/bjoc.2000.1523

[9] Ursic-Vrscaj, M., Kovacic, J., Poljak, M. and Marin, J. (1996) Association of Risk Factors for Cervical Cancer and Human Papilloma Viruses in Invasive Cervical Cancer. European Journal of Gynaecological Oncology, 17, 368-371.

[10] Daling, J.R., Madeleine, M.M., Mc Night, B., et al. (1996) The Relationship of Human Papillomavirus-Related Cervical Tumours to Cigarette Smoking, Oral Contraceptive Use, and Prior Herpes Simplex Virus Type 2 Infection. Cancer Epidemiology, Biomarkers \& Prevention, 5, 541-548.

[11] Cox, J.T. (1995) Epidemiology of Cervical Intraepithelial Neoplasia: The Role of Human Papillomavirus. Clinical Obstetrics and Gynecology, 9, 1-37.

[12] Lai, H.C., Sytwu, H.K., Sun, C.A., et al. (2003) Single Nucleotide Polymorphism at Fas Promoter Is Associated with Cervical Carcinogenesis. International Journal of Cancer, 103, 221-225. http://dx.doi.org/10.1002/ijc.10800

[13] Ueda, M., Terai, Y., Kanda, K., et al. (2006) Fas Gene Promoter-670 Polymorphism in Gynecological Cancer. International Journal of Gynecological Cancer, 16, 179-182. http://dx.doi.org/10.1111/j.1525-1438.2006.00505.X

[14] Kordi Tamandani, D.M., Sobti, R.C. and Shekari, M. (2008) Association of Fas-670 Gene Polymorphism with Risk of Cervical Cancer in North Indian Population. Clinical \& Experimental Obstetrics \& Gynecology, 35, 183-186.

[15] Zucchi, F., da Silva, I.D., Ribalta, J.C., et al. (2009) Fas/CD95 Promoter Polymorphism Gene and Its Relationship with Cervical Carcinoma. European Journal of Gynaecological Oncology, 30, 142-144.

[16] Dybikowska, A., Sliwinski, W., Emerich, J. and Podhajska, A.J. (2004) Evaluation of Fas Gene Promoter Polymorphism in Cervical Cancer Patients. International Journal of Molecular Medicine, 14, 475-478. http://dx.doi.org/10.3892/ijmm.14.3.475

[17] Engelmark, M.T., Renkema, K.Y. and Gyllesten, U.B. (2004) No Evidence of the Involvement of the Fas-670 Promoter Polymorphism in Cervical Cancer in Situ. International Journal of Cancer, 112, 1084-1085. http://dx.doi.org/10.1002/ijc.20515

[18] Zoodsma, M., Nolte, I.M., Schiper, M., et al. (2005) Interleukin-10 and Fas Polymorphism and Susceptibility for (Pre) Neoplastic Cervical Disease. International Journal of Gynecological Cancer, 15, 282-290. http://dx.doi.org/10.1111/j.1525-1438.2005.00433.x

[19] Kang, S., Dong, S.M., Seo, S.S., et al. (2008) Fas -1377G/A Polymorlhism and the Risk of Lymph Node Metastasis in Cervical Cancer. Cancer Genetics and Cytogenetics, 180, 1-5. http://dx.doi.org/10.1016/j.cancergencyto.2007.09.002

[20] Li, H., Guo, H.Y., Sun, T., et al. (2009) Association between Fas/FasL Genes Promoter Polymorphisms and Pathogenic Risk of Cervical Cancer. Chinese Journal of Oncology, 31, 38-41.

[21] Schneider, P., Bodmer, J.L., Holler, N., et al. (1997) Characterization of Fas (Apo-1, CD95)—Fas Ligand Interaction. Journal of Biological Chemistry, 272, 18827-18833. http://dx.doi.org/10.1074/jbc.272.30.18827

[22] Ashkenazi, A. and Dixit, V.M. (1998) Death Receptors: Signaling and Modulation. Science, 281, 1305-1308. http://dx.doi.org/10.1126/science.281.5381.1305

[23] Wajant, H. (2002) The Fas Signaling Pathway: More than a Paradigm. Science, 296, 1635-1636. 
http://dx.doi.org/10.1126/science.1071553

[24] Vaishnaw, A.K., Orlinick, J.R., Chu, J.-L., et al. (1999) The Molecular Basis for Apoptotic Defects in Patients with CD95 (Fas/Apo-1) Mutations. Journal of Clinical Investigation, 103, 355-363. http://dx.doi.org/10.1172/JCI5121

[25] Huang, Q.R., Morris, D. and Manopolios, N. (1997) Identification and Characterization of Polymorphisms in the Promoter Region of the Human APO-1/FAS (CD 95) Gene. Molecular Immunology, 34, 577-582. http://dx.doi.org/10.1016/S0161-5890(97)00081-3

[26] Huang, Q.R., Danis, V., Lassere, M., et al. (1999) Evaluation of a New Apo-1/Fas Promoter Polymorphism in Rheumatoidd Arthritis and Systemic Lupus Erythematosus Patients. Rheumatology, 38, 645-651.

[27] Niino, M., Kikuchis, A., Fukazawa, T., et al. (2002) An Examination of the Apo-1/Fas Promoter Mva I Polymorphism in Japanese Patients with Multiple Sclerosis. BMC Neurology, 2, 8-12. http://dx.doi.org/10.1186/1471-2377-2-8

[28] Boldrini, L., Faviana, P., Gisfredi, S., et al. (2002) Identification of Fas (Apo-1/CD95) and p53 Gene Mutations in Non-Small Cell Lung Cancer. International Journal of Oncology, 20, 155-159.

[29] Wang, L.E., Cheng, L., Spitz, M.R. and Wei, Q. (2003) Fas A670G Polymorphism, Apoptotic Capacity in Lymphocyte Cultures, and Risk of Lung Cancer. Lung Cancer, 42, 1-8. http://dx.doi.org/10.1016/S0169-5002(03)00276-9

[30] Jrad, B.B.H., Mahfouth, W., Bouaouina, N., et al. (2006) A Polymorphism in Fas Gene Promoter Associated with Increased Risk of Nasopharyngeal Carcinoma and Correlated with Anti-Nuclear Autoantibodies Induction. Cancer Letters, 233, 21-27. http://dx.doi.org/10.1016/j.canlet.2005.02.037

[31] Ueda, M., Hung, Y.-C., Terai, Y., et al. (2005) Fas Gene Promoter-670 Polymorphism (A/G) Is Associated with Cervical Carcinogenesis. Gynecologic Oncology, 98, 129-133. http://dx.doi.org/10.1016/j.ygyno.2005.04.001

[32] Ferreira, J.A.S. (1999) Perimenopause. In: Fernandes, C.E., Demelo, N.R. and Wehba, S., Eds., Climateric Women: Pathophysiology, Diagnosis and Treatment, Lemos Editorial, São Paulo, 13-26.

[33] FIGO Committee on Gynecologic Oncology, Benedet, J.L., Bender, H., Jones, H., et al. (2000) FIGO Staging Classifications and Clinical Practice Guidelines in the Management of Gynecologic Cancers. International Journal of Gynecology \& Obstetrics, 70, 209-262. http://dx.doi.org/10.1016/S0020-7292(00)90001-8

[34] Rudert, F., Visser, E., Forbes, L., et al. (1995) Identification of a Silencer, Enhancer, and Basal Promoter Region in the Human CD95 (Fas/Apo-1) Gene. DNA and Cell Biology, 14, 931-937. http://dx.doi.org/10.1089/dna.1995.14.931

[35] Adams, M.D., Fieldas, C. and Venter, J.C. (1994) Automated DNA Sequencing and Analysis. Academic Press, San Diego.

[36] Breslow, N.E. and Day, N.E. (1980) Statistical Methods in Cancer Research-The Analysis of Case-Control Studies. .IARC Sci Publ, 32, 5-338.

[37] Bosch, F.X. and De Sanjose, S. (2002) Human Papillomavirus in Cervical Cancer. Current Oncology Reports, 4, 175183. http://dx.doi.org/10.1007/s11912-002-0079-y

[38] Lee, S.H., Shin, M.S., Park, W.S., et al. (1999) Alterations of Fas (Apo-1/CD95) Gene in Transitional Cell Carcinomas of Urinary Bladder. Cancer Research, 27, 3068-3072.

[39] Lee, S.H., Shin, M.S., Park, W.S., et al. (1999) Alterations of Fas (Apo-1/CD95) Gene in Non-Small Cell Lung Cancer. Oncogene, 18, 3754-3760. http://dx.doi.org/10.1038/sj.onc.1202769

[40] Nelson, H.H., Kelsey, K.T., Bronson, M.H., et al. (2001) Fas/Apo-1 Promoter Polymorphism Is Not Associated with Non-Melanoma Skin Cancer. Cancer Epidemiology, Biomarkers \& Prevention, 10, 809-810.

[41] Seo, J.C., Han, S.W., Yin, C.S., et al. (2002) Evaluatin of a Apo-1/Fas Promoter Polymorphism in Korean Stroke Patients. Experimental \& Molecular Medicine, 34, 294-298. http://dx.doi.org/10.1038/emm.2002.41

[42] Lai, H.C., Lin, W.Y., Lin, Y.M., et al. (2005) Genetic Polymorphisms of FAS and FASL (CD95/CD95L) Genes in Cervical Carcinogenesis: An Analysis of Haplotype and Gene-Gene Interaction. Gynecologic Oncology, 99, 113-118. http://dx.doi.org/10.1016/j.ygyno.2005.05.010

[43] Park, S.H., Choi, J.E., Kim, E.J., et al. (2006) Polymorphisms in the FAS and FASL Genes and Risk of Lung Cancer in a Korean Population. Lung Cancer, 54, 303-308. http://dx.doi.org/10.1016/j.lungcan.2006.09.002

[44] Li-Weber, M. and Krammer, P.H. (2003) Function and Regulation of the CD95 (Apo-1/Fas) Ligand in the Immune System. Seminars in Immunology, 15, 145-157. http://dx.doi.org/10.1016/S1044-5323(03)00030-7

[45] Sepiashvili, R.A., Shubich, M.G., Kolesnikova, N.V., et al. (2001) Apoptosis in Immunologic Process. Clinical and Applied Immunology Reviews, 1, 163-172. http://dx.doi.org/10.1016/S1529-1049(01)00024-1

[46] Mor, G., Straszewski, S. and Kamsteeg, M. (2002) Role of the Fas/Fas Ligand System in Female Reproductive Organs: Survival and Apoptosis. Biochemical Pharmacology, 64, 1305-1315. http://dx.doi.org/10.1016/S0006-2952(02)01267-4

[47] Butler, L.M., Hewett, P.J., Butler, W.J. and Cowled, P.A. (1998) Down-Regulation of Fas Gene Expresson in Colon 
Cancer Is Not a Result of Allelic Loss or Gene Rearrangement. British Journal of Cancer, 77, 154-159. http://dx.doi.org/10.1038/bjc.1998.239

[48] Shimonishi, T., Isse, K., Shibata, F., et al. (2000) Up-Regulation of Fas Ligand at Early Stages and Down-Regulation of Fas at Progressed Stages of Intrahepatic Cholangiocarcinoma Reflect Evasion from Immune Surveillance. Hepatology, 32, 761-769. http://dx.doi.org/10.1053/jhep.2000.18192

[49] Lee, Y.H., Kim, Y.R., Ji, J.D., et al. (2001) Fas Promoter-670 Polymorphism Is Associated with Development of Anti-RNP Antibodies in Systemic Lupus Erythematosus. The Journal of Rheumatology, 28, 2008-2011.

[50] Das, H., Koizumi, T., Sugimoto, T., et al. (2000) Quantitation of Fas and Fas Ligand Gene Expression in Human Ovarian, Cervical and Endometrial Carcinomas Using Real-Time Quantitative RT-PCR. British Journal of Cancer, 82, 1682-1688.

[51] Sun, T., Zhou, Y., Li, H., et al. (2005) FASL -844C Polymorphism Is Associated with Increased Activation-Induced T Cell Death and Risk of Cervical Cancer. The Journal of Experimental Medicine, 202, 967-974. http://dx.doi.org/10.1084/jem.20050707

[52] Schiffman, M.H. and Castle, P.E. (2003) Human Papillomavirus: Epidemiology and Public Health. Archives of Pathology \& Laboratory Medicine, 127, 930-934.

[53] Au, W.W., Sierra-Torres, C.H. and Tyring, S.K. (2003) Acquired and Genetic Susceptibility to Cervical Cancer. Mutation Research, 544, 361-364. http://dx.doi.org/10.1016/j.mrrev.2003.05.001

[54] Zhang, X., Miao, X., Sun, T., et al. (2005) Functional Polymorphisms in Cell Death Pathway Genes FAS and FASL Contribute to Risk of Lung Cancer. Journal of Medical Genetics, 42, 479-484. http://dx.doi.org/10.1136/jmg.2004.030106

[55] Sun, T., Miao, X., Zhang, X., et al. (2004) Polymorphism of Death Pathway Genes FAS and FASL in Esophageal Squamous Cell Carcinoma. Journal of the National Cancer Institute, 96, 1030-1036. http://dx.doi.org/10.1093/jnci/djh187

[56] Suzuki, N., Wakisoka, S., Tokeba, Y., et al. (1999) Effects of Cigarette Smoking on Fas/Fas Ligand Expression of Human Lymphocytes. Cellular Immunology, 25, 48-53. http://dx.doi.org/10.1006/cimm.1998.1432

[57] Bijl, M., Horst, G., Limburg, P.C. and Kallemberg, C.G. (2001) Effects of Smoking on Activation Markers, Fas Expression and Apoptosis of Peripheral Blood Lymphocytes. European Journal of Clinical Investigation, 31, 550-553. http://dx.doi.org/10.1046/j.1365-2362.2001.00842.x

[58] Winkelstein Jr, W. (1990) Smoking and Cervical Cancer-Currents Status: A Review. American Journal of Epidemiology, 131, 945-957.

[59] Simons, A.M., Phillips, D.H. and Coleman, D.V. (1993) Damages to DNA in Cervical Epithelium Related to Smoking Tobacco. The BMJ, 306, 1444-1448. http://dx.doi.org/10.1136/bmj.306.6890.1444

[60] Schiffman, M., Bauer, H., Hoover, R., et al. (1993) Epidemiologic Evidence Showing That Human Papillomavirus Infection Causes Most Cervical Intraepithelial Neoplasia. Journal of the National Cancer Institute, 85, 958-964. http://dx.doi.org/10.1093/jnci/85.12.958

[61] Eluf-Neto, J., Booth, M., Muñoz, N., et al. (1994) Human Papillomavirus and Invasive Cervical Cancer in Brazil. British Journal of Cancer, 69, 114-119. http://dx.doi.org/10.1038/bjc.1994.18

[62] Moreno, V., Bosch, F.X., Muñoz, N., et al. (2002) Effect of Oral Contraceptives on risk of Cervical Cancer in Women with Human Papillomavirus Infection: The IARC Multicentric Case-Control Study. The Lancet, 359, 1085-1092. http://dx.doi.org/10.1016/S0140-6736(02)08150-3

[63] Eppel, W., Worda, C., Frigo, P., et al. (2000) Human Papillomavirus in the Cervix and Placenta. Obstetrics \& Gynecology, 96, 337-341. http://dx.doi.org/10.1016/S0029-7844(00)00953-4

[64] Vaux, D.L. and Flavell, R.A. (2000) Apoptosis Genes and Autoimmunity. Current Opinion in Immunology, 12, 719724. http://dx.doi.org/10.1016/S0952-7915(00)00168-0

[65] Jackson, C.E., Fischer, R.E., Hsu, A.P., et al. (1999) Autoimmune Lymphoproliferative Syndrome with Defective Fas: Genotype Influences Penetrance. The American Journal of Human Genetics, 64, 1002-1014. http://dx.doi.org/10.1086/302333

[66] Resqué, R.L., Freitas, N.S.C., Rodrigues, E.M.R., et al. (2010) Estimates of Interethnic Admixture in the Brazilian Population Using a Panel of 24 X-Linked Insertion/Deletion Markers. American Journal of Human Biology, 22, 849852. http://dx.doi.org/10.1002/ajhb.21089 